\title{
Very Late Bare Metal Stent Thrombosis Presenting with Acute Myocardial Infarction: 14 Years after Coronary Stenting
}

\author{
Toshiro Katayama, Fumi Yamamoto, Masahiko Ishizaki and Yoshihiro Iwasaki
}

\begin{abstract}
Fourteen years previously, a 67-year-old man underwent percutaneous coronary intervention (PCI) for proximal left anterior descending artery lesion with a bare metal stent (BMS) for acute myocardial infarction (AMI) and attained an excellent result. Ticlopidine $(200 \mathrm{mg}$ ) was administered for one month and $100 \mathrm{mg}$ of aspirin was daily has been continued. One year after PCI, coronary angiography showed no restenosis. However, 14 years after PCI, he suffered from AMI due to stent thrombosis. Intracoronary aspiration thrombectomy and implantation of a drug-eluting stent were successful. This report demonstrates evidence of a very late case of stent thrombosis with the use of BMS.
\end{abstract}

Key words: bare metal stent, late stent thrombosis, acute myocardial infarction

(Inter Med 49: 1549-1552, 2010)

(DOI: 10.2169/internalmedicine.49.3337)

\section{Introduction}

Coronary stenting has revolutionized the practice of interventional cardiology. It has dramatically improved upon the acute procedural success and also reduced the restenosis rates observed with balloon angioplasty alone (1).

Although rare, the incidence of stent thrombosis is associated with a high frequency of major adverse clinical consequences. Its estimated 30-day mortality ranges from 20 to $48 \%$ and can cause myocardial infarction in $60-70 \%$ of patients (2).

The most recently accepted definition established by the Academic Research Consortium classifies stent thrombosis as: early (occurring within 30 days), late (30 days to 1 year), or very late (after 1 year). Very late stent thrombosis has been reported following drug-eluting stent implantation with rates up to $0.3-0.6 \%$ per year and has been attributed to delayed strut endotheliazation $(2,3)$. It is distinctly unusual with the use of BMS, because the stent endotheliazation is considered to be completed four weeks after the intervention (4).

\section{Case Report}

A 67-year-old male with hypertension and hyperlipidemia was referred for anterior acute myocardial infarction (AMI). Coronary angiography (CAG) showed a significant stenotic lesion in the proximal-segment of the left anterior descending coronary artery (LAD) (Fig. 1A). He had undergone percutaneous coronary intervention (PCI) for proximal LAD lesion with a bare metal stent (Palmatz-Shatz stent 3.0×15 $\mathrm{mm}$ ) and had an excellent angiographic result (Fig. 1B). The peak creatine kinase value was only $564 \mathrm{IU} / \mathrm{L}$ at this first infarction. The left ventricular ejection fraction at this time was $64 \%$ by ultrasound cardiogram, and anterior wall motion was well preserved, suggesting that the viability of the infarcted region affected by first attack was maintained. Ticlopidine $(200 \mathrm{mg}$ ) was administered for one month and 100 $\mathrm{mg}$ daily of aspirin was daily continued. Other medications were $10 \mathrm{mg}$ of pravastatin and $20 \mathrm{mg}$ of nifedipine. His drug compliance was satisfactory, and the level of blood pressure was controlled within normal range. Six months later, and one year later after implantation of the stent, CAG showed no restenosis (Fig. 1C). On quantitative coronary ar-

Department of Cardiology, Nagasaki Kouseikai Hospital, Nagasaki

Received for publication January 4, 2010; Accepted for publication April 15, 2010

Correspondence to Dr. Toshiro Katayama, katatoshiyamarou@ybb.ne.jp 


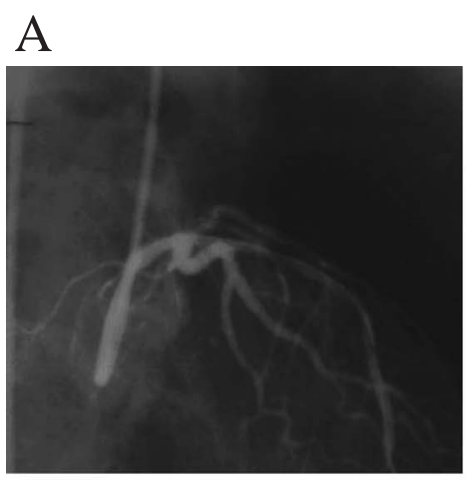

D

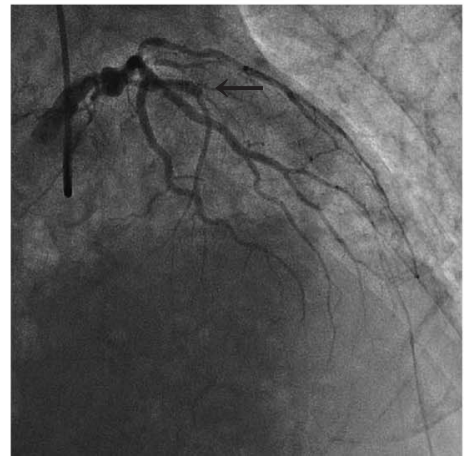

B

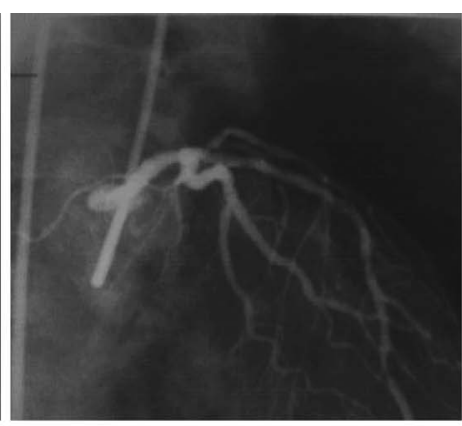

E
C
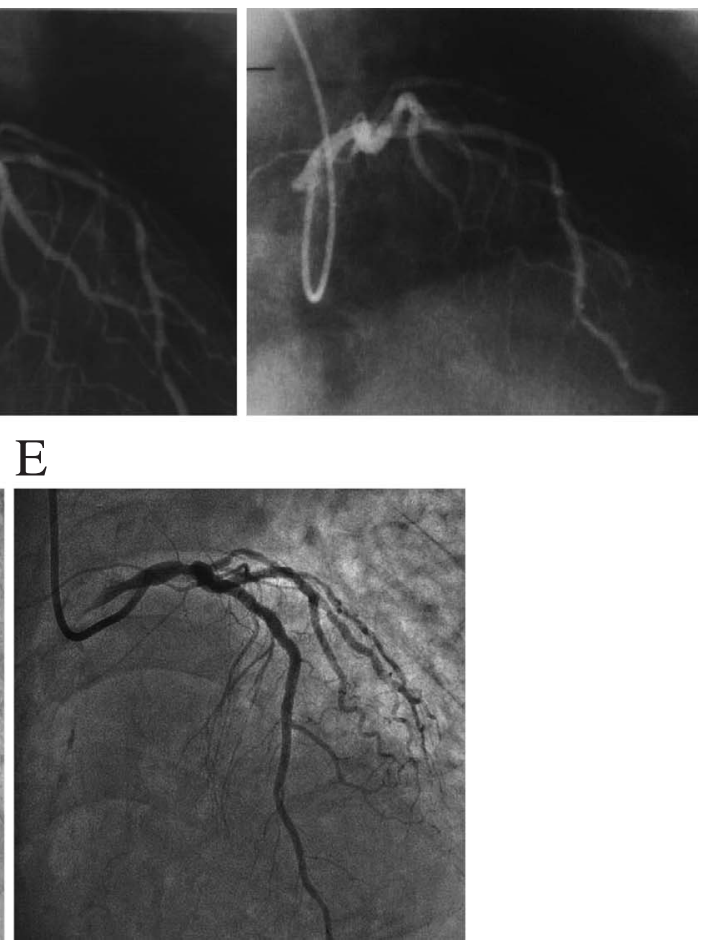

Figure 1. Coronary angiography. (A) Baseline coronary angiography, 14 years previously, showing a significant lesion in the proximal-segment of the left anterior descending (LAD) coronary artery. (B) Postprocedural coronary angiography after percutaneous coronary intervention (PCI) with a bare metal stent in the LAD. (C) Coronary angiography 12 months after the PCI showing no significant stenosis. (D) Coronary angiography 14 years after the PCI showing total occulusion at the proximal edge of the stent. (arrow) (E) Postprocedural coronary angiography after the recent PCI with the drug eluting stent in the LAD.
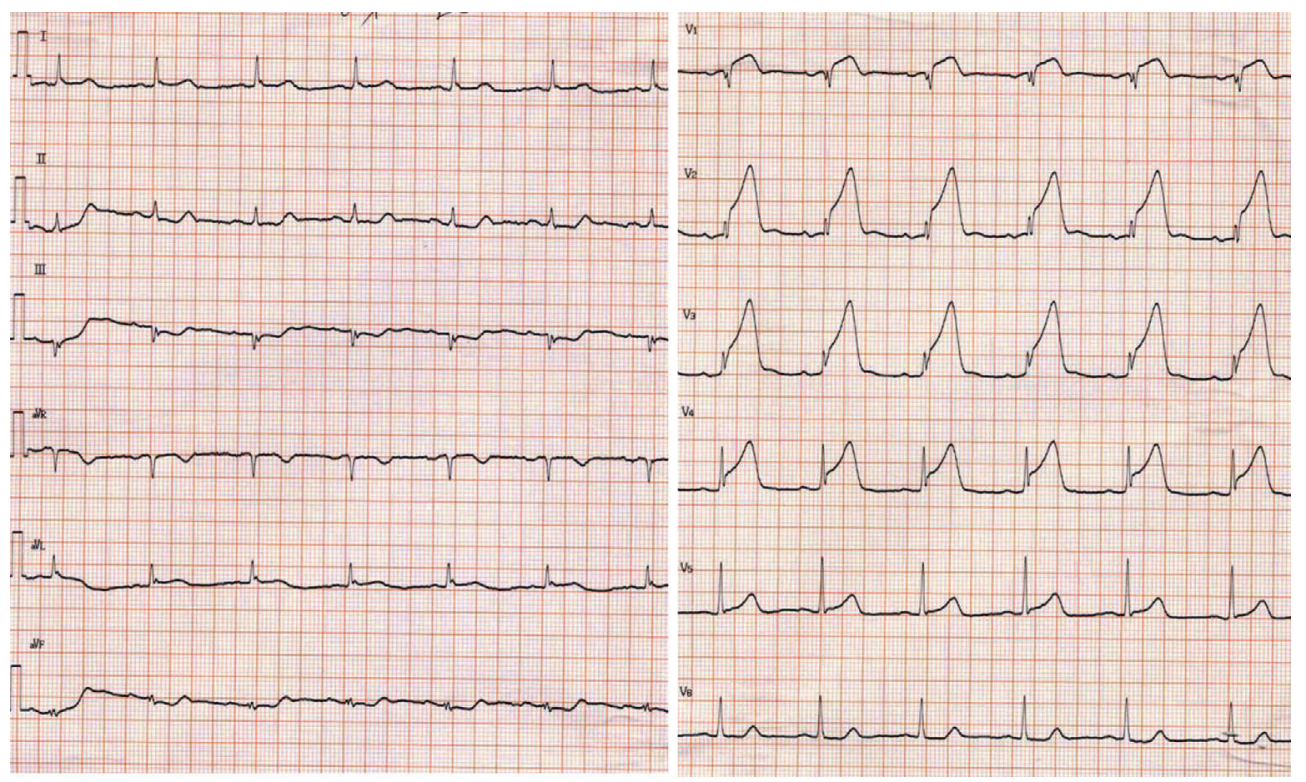

Figure 2. On admission after the second MI attack, ECG showed ST elevation in V1-4 leads.

teriography (QCA), the \% diameter stenosis (\%DS) of the proximal stent edge was $24 \%$. Fourteen years later after implantation of stent, he developed acute chest pain and his resting ECG showed ST elevation in V1-4 leads (Fig. 2). He was immediately referred for angiography the same day. On admission, the level of LDL cholesterol was $136 \mathrm{mg} / \mathrm{dL}$ and the level of highly sensitive C-reactive protein (hs-CRP) was $1.2 \mathrm{mg} / \mathrm{dL}$. CAG showed total occlusion at the entrance of the proximal stent in the LAD lesion (Fig. 1D, arrow). After positioning of a 6 French FL 3.5 guiding catheter (Boston 

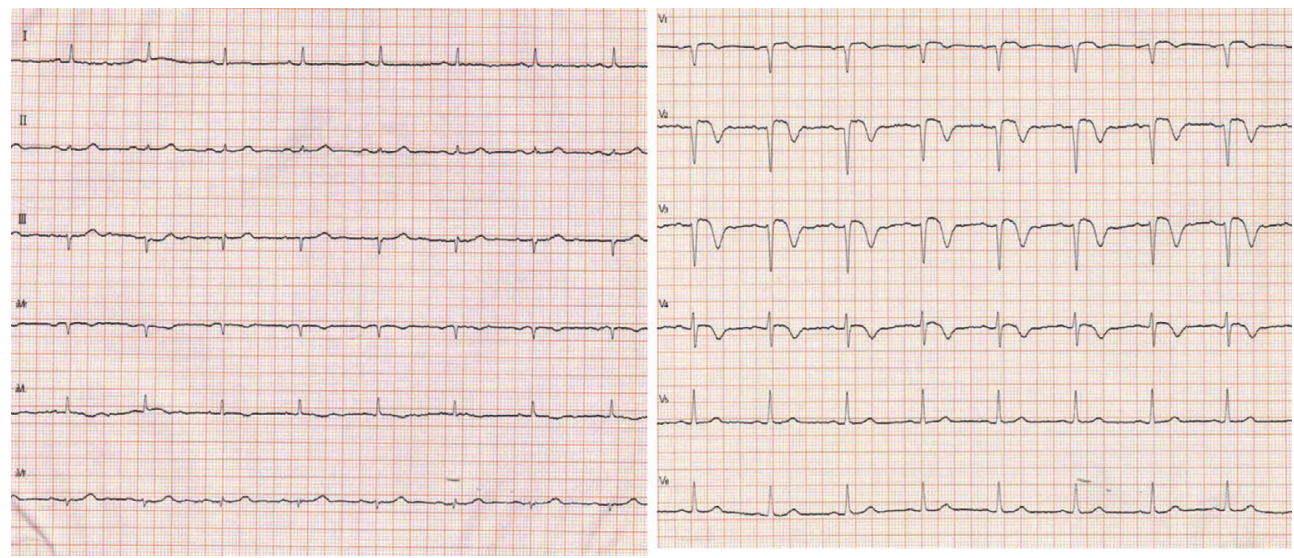

Figure 3. After stent implantation, the ST elevation of chest leads normalized immediately, and proper ST resolution was obtained.

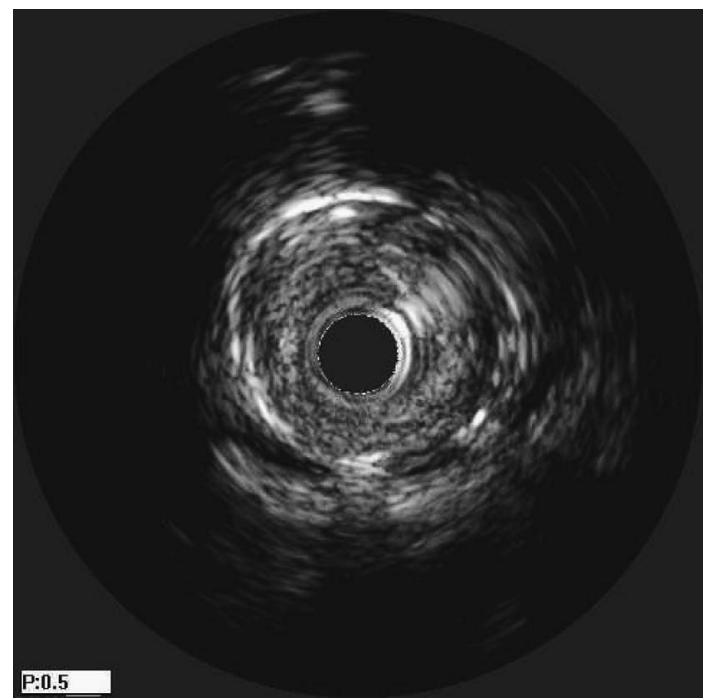

Figure 4. Intravascular ultrasound image. IVUS image confirmed a tight fibrotic in-stent hyperplasia and thrombus.

Scientific, Watertown, MA), a 0.014 in. Runthrough Guidewire (Terumo, Tokyo) was passed across the occlusion. An intravascular ultrasound (IVUS) catheter (CVISdevice, Boston Scientific) was then employed to reveal the underlying cause of this occlusive lesion. The IVUS catheter was advanced distal to the lesion, and imaging was performed retrograde through the proximal reference artery at a pullback speed at $0.5 \mathrm{~mm} / \mathrm{s}$ automatically. IVUS image confirmed a tight fibrotic in-stent hyperplasia and thrombus (Fig. 4). Then, intracoronary aspiration thrombectomy was successful. After that he was treated with balloon angioplasty and a drug-eluting stent (TAXUS Liverte stent $3.0 \times 28 \mathrm{~mm}$, Boston Scientific) for LAD, and TIMI 3 coronary flow was obtained (Fig. 1E). After stent implantation, the ST elevation of chest leads was normalized immediately, in other words, proper ST resolution was achieved (Fig. 3). Few days later, the pathological findings revealed that the aspiration material was fresh thrombus. We described a patient with acute myocardial infarction who had late stent thrombosis 14 years after stent implantation.

\section{Discussion}

Stent thrombosis is a catastrophic complication that frequently presents as an acute myocardial infarction and/or sudden cardiac death. Stent thrombosis has in large part been overcome by the use of high-pressure inflation and the aggressive use of antiplatelet agents such as aspirin and either ticlopidine or clopidogrel (5).

Because bare metal stent endotheliazation is considered to be complete after four weeks of the intervention, late stent thrombosis is distinctly unusual with the use of BMS (4).

On the other hand, late stent thrombosis is increasingly being recognized as a complication of drug-eluting stents where it may be related to delayed endotheliazation (6). Brachytherapy trials have also identified the phenomenon of late stent thrombosis, because brachytherapy caused slow progression of pathophysiologic process of the neointimal hyperplasia (7).

It is reported that late stent thrombosis with drug-eluting stent occurs with an incidence of $0.3 \%$ to $1.0 \%(2,3)$. Some recent reports indicated that the incidence of stent thrombosis did not differ significantly between patients with drugeluting stents and those with bare-metal stents (7-9). Independent predictors of stent thrombosis were premature antiplatelet therapy discontinuation, renal failure, bifurcation lesions, diabetes, and a lower ejection fraction $(2,5)$.

The incidence of definite very late stent thrombosis after BMS implantation seems to be very low, as only 21 cases could be identified in the Medline literature, despite the deployment of millions of BMS over the past decade. To the best of our knowledge, very late thrombosis of BMS has been reported within 10 years after stent implantation (8).

Our report demonstrated evidence of the latest case of stent thrombosis with the use of BMS.

The pathophysiology of very late stent BMS thrombosis is poorly defined. Of course we should consider the potential existence of conditions, which may facilitate the formation of thrombus, because the present case experienced acute coronary syndrome twice. However, he has no factor to fa- 
cilitate thrombus formation, such as collagen disease, abnormality of coagulation, dehydration, renal insufficiency. We could not deny the possibility of arrhythmia, such as paroxysmal atrial fibrillation. Presumed causes of bare metal stent thrombus, both early and late, include noncompliance with antiplatelet agents, exercise-induced procoaglant state, brachytherapy, small stent size, and underdeployment of stent (9).

In the present case, IVUS image confirmed a tight fibrotic in-stent hyperplasia and thrombus. By the pathological finding, the aspiration material was fresh thrombus. These data suggest that BMS restenosis was the main pathologic mechanism leading to abrupt thrombotic vessel closure. The insufficient control of LDL cholesterol might lead to the rupture of the lipid-rich plaque. Further, the level of hs-CRP of this case was elevated at the time of second MI attack. Kimura et al described that pathological analysis of the stented human coronary arteries demonstrated heavy infiltration of lipid-laden macrophages around the struts beyond 5 years after coronary stenting, which indicating chronic inflammatory reactions. This chronic inflammation might induce late atherosclerotic progression of the treated le- sions (10). In the present case, this chronic inflammation might also lead to the luminal renarrowing beyond 10 years and plaque rupture. In-stent restenosis has been commonly believed to be a benign process due to its stable clinical presentation, as a result of slow and progressive neointimal proliferation and smooth muscle cell migration. However, as a matter of fact, in-stent restenosis presents as acute myocardial infarction in 3.5 to $19.4 \%$ of patients, and as such is not always a benign process $(8,11)$.

We descrived a case of late coronary stent thrombosis which manifested as AMI 14 years after stenting. This case is, to our knowledge, the latest case of stent thrombosis with the use of BMS.

\section{Conclusion}

To the best of our knowledge, the most delayed case of BMS thrombosis is ten years after stent implantation. In the present case, late thrombosis occurred about fourteen years after implantation of bare metal stent implantation. Our report demonstrated evidence of the latest case of stent thrombosis with the use of bare metal stent.

\section{References}

1. Serruys PW, de Jaegere P, Kiemeneij F, et al. A comparison of balloon-expandable-stent implantation with balloon angioplasty in patients with coronary artery disease. Benestent Study Group. N Engl J Med 331: 489-495, 1994.

2. Cutlip DE, Baim DS, Ho KK, et al. Stent thrombosis in the modern era: A pooled analysis of multicenter coronary stent trials. Circulation 103: 1967-1971, 2001.

3. Kimura T, Morimoto T, Nakagawa Y, et al. Antiplatelet therapy and stent thrombosis after sirolimus-eluting stent implantation. Circulation 119: 987-995, 2009.

4. Wenaweser P, Rey C, Eberli FR, et al. Stent thrombosis following bare-metal stent implantation: success of emergency percutaneous coronary intervention and predictors of adverse outcome. Eur Heart J 26: 1180-1187, 2005.

5. Mehta SR, Yusuf S, Peters RJ, et al. Clopidogrel in unstable angina to prevent recurrent events trial (CURE) Investigators. Effects of pretreatment with clopidgrel and aspirin followed by long-term therapy in patients undergoing percutaneous coronary intervention: The PCI-CURE study. Lancet 358: 527-533, 2001.

6. Ong AT, McFadden EP, Regar E, de Jaegere PP, van Domburg RT,
Serruys PW. Late angiographic stent thrombosis (LAST) events with drug-eliting stents. J Am Coll Cardiol 45: 2088-2092, 2005.

7. Costa MA, Sabate M, van der Giessen WJ, et al. Late coronary occlusion after intracoronary brachytherapy. Circulation 100: 789792, 1999.

8. Lemesle G, Pinto Slottow TL, Waksman R. Very late stent thrombosis after bare-metal stent implantation: case reports and review of the literature. J Invasive Cardiol 21: 27-32, 2009.

9. Trabattoni D, Bartorelli AL. Late occlusive in-stent restenosis of a bare-metal stent presenting with ST-elevation anterior MI: is restenosis better than a late stent thrombosis? Int J Cardiol 135: 65-67, 2009.

10. Kimura T, Abe K, Shizuta S, et al. Long-term clinical and angiographic follow-up after coronary stent placement in native coronary arteries. Circulation 105: 2986-2991, 2002.

11. Bossi I, Klersy C, Black AJ, et al. In-stent restenosis: long-term outcome and predictors of subsequent target lesion revascularization after repeat balloon angioplasty. J Am Coll Cardiol 35: 15691576, 2000.

(C) 2010 The Japanese Society of Internal Medicine http://www.naika.or.jp/imindex.html 